\title{
Bodies and Documents: The Material Impact of Collaborative Information- Sharing Within the Seasonal Agricultural Worker Program
}

\author{
Courtney Jane Clause* \\ Carleton University, Communication and Journalism, Ottawa, ON, Canada
}

OPEN ACCESS

Edited by:

Constance Gordon,

San Francisco State University,

United States

Reviewed by:

Daniela Manuschevich,

University of Chile, Chile

Voltaire Alvarado Peterson,

University of Concepcion, Chile

Sonia Rains Ivancic,

University of South Florida,

United States

Kristen Okamoto,

Clemson University, United States

${ }^{*}$ Correspondence:

Courtney Jane Clause

janeclause@cmail.carleton.ca

Specialty section: This article was submitted to

Science and Environmental

Communication,

a section of the journal

Frontiers in Communication

Received: 10 February 2021 Accepted: 02 November 2021 Published: 23 December 2021

Citation:

Clause CJ (2021) Bodies and Documents: The Material Impact of Collaborative Information- Sharing

Within the Seasonal Agricultural Worker Program.

Front. Commun. 6:666652. doi: $10.3389 /$ fcomm.2021.666652
This study examines information-sharing practices within the Seasonal Agricultural Worker Program (SAWP), focusing on the program as it is administered within Ontario. I analyze 61 documents for their content, codification of stakeholder relationships, and discourse regarding the program. Documents were selected based on their creation, use, or circulation within Ontario, and based on the likelihood that at least one stakeholder group would look to the document for (what they perceive to be) reliable information. Documents include, for example, SAWP contracts, webpages describing program requirements, and e-pamphlets on workplace safety and accessing services. Document analysis was supplemented by interviews with industry and service provider experts, which guided interpretation of documents' significance. I argue that documents function as material actors, alongside (and sometimes beyond) human actors, and make physical impact on SAWP bodies and realities. Documents construct and uphold neoliberal structures surrounding the program by contributing to the creation and sustaining of incomplete, labour-centric individuals. Through consistent sharing of narrow, "work" information, and the rare inclusion of more well-rounded, "non-work" knowledge, documents subtly discipline the boundaries of acceptable and unacceptable communication. In doing so, material actors (alongside other SAWP actors) perpetuate a foreign worker program which does not consider the varied, complex needs of whole persons but, instead, treats them as disposable labouring bodies.

Keywords: migration, labour, agriculture, disciplinary power, discourse, information, access

\section{INTRODUCTION}

This article examines information-sharing within Canada's Seasonal Agricultural Worker Program (SAWP) as it relates to long-standing flaws within the program's ability to foster effective communication with (and among) workers and other SAWP stakeholders. These flaws include: language barriers (Mysyk et al., 2009; Paz Ramirez, 2013), inadequate translation services (Mysyk et al., 2009), unclear program processes (Vosko, 2018, p. 902), insufficient job training (Paz Ramirez, 2013; Caxaj and Cohen, 2019), constrained access to information on worker rights (McLaughlin and Weiler, 2019, p. 3), weak inter-governmental and cross-agency communication (Nakache and Kinoshita, 2010; Braun, 2012), minimal communication with the public on key issues (Nakache \& Kinoshita, 2010), and lack of support in understanding formal and informal infrastructure (Basok et al., 2014; McLaughlin et al., 2017; Caxaj and Cohen, 2019). Though access to information finds 
mention in several scholarly works on SAWP, few, if any, have dedicated study to knowledge-sharing as the main question. Yet, migrant workers have been speaking to these issues for a number of years (Paz Ramirez, 2013; Basok et al., 2014; McLaughlin and Weiler, 2019), and have highlighted the importance of clear and comprehensive information to their safety and wellbeing (United Food and Commercial Workers Canada and Agricultural Worker Alliance, 2020).

My study intervenes in this literature, and aims to include information-sharing more fully among scholarly discussions of SAWP's varied harms - understanding it as a significant concern (Caropresi, 2013) along interrelated spectrums of oppression (Thomas et al., 2016; Strauss and McGrath, 2017). Extending SAWP literature on the prevalence of neoliberal structures within program spaces (Paz Ramirez, 2013; Preibisch, 2010; Braun, 2012; Basok, et al., 2014), I argue that SAWP's discursive practices represent another dimension contributing to the disciplining of program bodies towards neoliberal ends. Documentation perpetuates de-collectivizing and the minimizing of laboursocial intersections (McLaughlin et al., 2017; Paz Ramirez, 2013) through its representation of relevant program stakeholders, needs, and dimensions of life. These representations invariably favour labour and industry concerns over social, familial, and communal wellbeing. As with other areas of SAWP, ${ }^{1}$ this inattention to "whole workers" (Jane McAlevey, cited in McLaughlin et al., 2017) contributes to the creation and sustaining of disposable labouring bodies, as we "import workers, not people" (Preibisch, 2010, p. 432).

Given these discursive harms, I discuss the possibilities of attending to information and its tools. Information represents a shared and collaborative need among stakeholders (Participant 3 , farm-owner, 2019; Participant 4, NGO, 2019; Caropresi, 2013) amid a historically polarizing program, and may reinvigorate principles of shared responsibility. Documents represent a meeting place where, “. . as one writes about oneself to others, and as others write back, what one can say of oneself transforms, until one contests the limits of one's discursive position" (Sheldahl-Thomason, 2018, p. 131). Further, I suggest that consideration of how documents act within SAWP spaces encourages relational and ethical interactions with all program agents (human and non-human), which allows us to consider what "good information" and "good documents" might mean for future SAWP realities-that is, the program we hope to see.

\section{Background on SAWP}

SAWP began in 1966 as a pilot project intended to combat (real or perceived) labour shortages in Canada (Preibisch and Hennebry, 2011, p. 20). Under SAWP, Canadian farms (growing produce from a list of specified commodities) can apply to host and employ SAWP enrollees from Mexico and eleven Caribbean countries as follows: “. . for a maximum period of 8 months, between January 1 and December 15, provided they are able to offer the workers a minimum of 240 hours of work

${ }^{1}$ For example, the physical disciplining of intra-workplace socializing. See Paz Ramirez, 2013. within a period of 6 weeks or less" (Government of Canada, 2020a, para. 2). In 2014, SAWP accepted 35,000 workers (Canadian Agricultural Human Resource Council, 2017), with 17,968 of those workers labouring in the province of Ontario (Agri-Food Economic Systems, 2015, p. 6). ${ }^{2}$ SAWP workers are concentrated predominantly in Ontario $^{3}$ and Quebec, with British Columbia and Alberta holding the next highest populations (McLaughlin, 2009; Preibisch, 2012). The majority of these workers travel from Mexico; in 2013, 18,499 enrollees from Mexico worked in Canadian provinces (Consulado General de México en Toronto, 2016). The administrative structure of SAWP carries distinct challenges and vulnerabilities. Workers travel to Canada under employer-specific work permits, meaning that loss of employment, whether through dismissal or resignation, necessitates deportation (Basok et al., 2014). Worker housing is a farm-owner responsibility, typically located on-farm or on an off-site employer-owned property, and amounts to a totalizing environment for working, living, and socializing. This system implies, even if employers do not explicitly exercise, control and surveillance (Paz Ramirez, 2013; McLaughlin, et al., 2017). Workers contribute to various employment benefits on a mandatory basis, but are unable to collect some (e.g., employment insurance) as they cannot remain in the country if they are unemployed (MacLean \& McLaughlin, 2018). Importantly, the program is administered within contexts of neoliberalism, which require disposable, cheap, racialized labour to sustain contemporary capitalism. Following scholars like Brown (2015), I conceptualize neoliberalism as a normative rationale that permeates the everyday (p. 30). Through discourses of economization spread throughout all spheres of life, neoliberalism enables the production of subjects in the form of these disposable, labouring bodies (p. 21).

As SAWP impacts a vast number of life and labour concerns, relevant documents included in this study are similarly varied. Documents may be created by government agencies, non-profit groups, service providers, health organizations, workplace organizations, or other local groups. Information within documents may be aimed at supporting farm-owners, service providers, and/or SAWP enrollees in fulfilling their various roles within the program.

\section{METHODS}

In this study, I employ a conceptual framework which blends theories on non-human agency, materiality, and power, both within and beyond Foucauldian thought, and Critical Discourse Analysis (CDA). Following other scholars, I understand CDA to

\footnotetext{
${ }^{2}$ With the introduction of a new temporary foreign worker program (TFWP) structure, statistics for SAWP admissions have been combined with other agriculture programs (e.g., primary agriculture stream). However, in 2018, Statistics Canada reports that 54,734 temporary foreign workers (TFWs) were employed within the agricultural sector (Statistics Canada, 2020, para. 7).

${ }^{3}$ In 2017, Ontario's agricultural sector employed 97,800 people, $28 \%$ of Canada's agricultural workforce (Canadian Agricultural Human Resource Council, 2019, para. 2).
} 
function as both theory and method (Knezevic, 2011). Foucauldian and non-human agency theories bring important insights on the interrelated existence of documents, bodies, and power, where documentation is understood as a disciplinary and self-disciplinary action on bodies and spaces. CDA bolsters the Foucauldian framework with its long history of thought on neoliberalism and (new)capitalism. In addition, CDA tempers Foucault's penchant to get "caught up in the verbal" (Meyer \& Wodak, 2001, p. 20) and occasionally fail to acknowledge the physicality and physical impact of text (Butler, 1990). Each framework is discussed below.

\section{Foucault, and Other Theories on Materiality and Agency}

Foucauldian theories are well-established within SAWP studies for their pertinence to issues of power, governance, and nuanced or indirect expressions of violence (Preibisch \& Hennebry, 2011; Braun, 2012; Paz Ramirez, 2013; Basok et al., 2014; Basok \& Bélanger, 2016; McLaughlin et al., 2017). In Foucault's work, “complex documentary organization [s]" (Foucault, 1995, p. 214) are often instrumental in discipline and control. He argues that the practice of recording can tangibly shift the trajectories of lives (2000, p. 161). Here, documentation is an exercising of power that alters physical realities. Discursive practices create categories, indexes, and observations that render bodies and their actions visible or invisible, normal or abnormal, with important consequences for bodies (Foucault, 1995; Foucault, 2000). Though scholars have noted that Foucault's work is at times devoid of "thingness" (Butler, 1990; Elden \& Crampton, 2007, p. 56), in some of Foucault's work, there is a sustained engagement with documents as "things" acting on and with bodies (Elden \& Crampton, 2007; Sheldahl-Thomason, 2018). The mobilization of documents to discipline populations is thus crucial to questions of labour ${ }^{4}$, migration, and the expression of rights, resistance, and life within these spheres.

Non-human and textual agency, more broadly, adds to conceptualization of materiality, power, and action in this vein. Theories within these areas allow for a hybridity of human and non-human action, where organizational texts display levels of agency by "...participat [ing] in the channeling of behaviors, constitut [ing] and stabiliz [ing] organizational pathways, and broadcast [ing] information/ orders" (Cooren, 2004, p. 388). The idea here being that texts contribute to, or go beyond, human action with their particular abilities to mobilize across space and time, legitimize authorities and standards, and mold behaviours (Cooren, 2004; Kuhn, 2008, p. 1236, p. 388). Texts structure the values, knowledge, roles, and duties of human actors within specific organizations and

${ }^{4}$ Importantly, these are issues of racialized labour. This study is not able to fully address issues of race across information-sharing and documentation networks, as these dynamics involve nuanced and heterogenous racial identities. Studies which successfully examine race as it relates to SAWP (Braun, 2012; Vosko, 2013) typically focus on one racialized identity, sending country, etc. organizational settings through the creation of "authoritative texts" which come to represent the whole (Kuhn, 2008, p. 1236).

\section{Critical Discourse Analysis}

As mentioned above, CDA is discussed both as theory and method. Updates to Fairclough's tradition which, influenced by post-structuralism (Robinson, 2016, p. 117), acknowledge that reality shapes and is shaped by language have been conceptually useful to SAWP (and related) studies. There is a fairly substantial body of work within labour/migration fields which employs CDA to examine "...interrelated elements such as social relations, power, institutions, and cultural values..." (Cheng, 2016, p. 2513), as well as neoliberalism (Bennett, 2018), construction of the Other (Vickers and Rutter, 2018), and similar themes, as they are co-constituted within text. Following works like these, within my study, CDA offers ideas on the physical realities of capitalism, neoliberalism, and power as they relate to language and texts. These are discussed below.

As with a Foucauldian framework, CDA asserts that documents, text, and language are significant, even when they appear insignificant, objective, or "dry" (Foucault, 2000). This is particularly crucial when examining administrative program documents, which seek to provide "just-the-facts." On their surface, and for some intended uses, these documents do not (appear to) communicate meaningfully about the program's political or social significance. CDA provides a toolbox for illuminating the impact of subtext and absences within language. As Fairclough notes, CDA claims to "help correct the widespread underestimation of the significance of language in production, maintenance, and change of social relations of power" (Fairclough, 2014, p. 45).

Further, CDA brings a rich tradition of capitalist, new capitalist, and neoliberal critique. Those utilizing CDA have sought to analyze "narratives of progress" which center capital growth (Fairclough, 2000, p. 148). Within labour studies broadly, CDA is often used to analyze discursive and textual tools employed for the creation of individualized and productive citizens within a neoliberal context of privatization, responsibilization, and deregulation (Bennett, 2018; Shin and Ging, 2019). CDA studies have situated migratory labour within capitalist systems which increasingly require flexible, disposable workforces (Preibisch and Hennebry, 2011; Basok and Bélanger, 2016; Bennett, 2018), and are characteristic of governments which outsource and download responsibility (Franck and Anderson, 2019) to maximize economic benefits. These themes are crucial to the study of SAWP broadly, and are additionally useful in understanding its discursive world more narrowly, as scholars note program language possesses a disproportionate economic focus (Satzewich, 2007; Bauder, 2008; McLaughlin et al., 2017; Vosko, 2018).

As some scholars have noted Foucault's tendency to get "caught up in the verbal" (Meyer and Wodak, 2001, p. 20), CDA lastly provides some necessary conceptual counterparts. In understanding relationships between discursive practices and realities, $\mathrm{CDA}$ assumes a relatively material (but not deterministic) perspective. CDA allows for "the mediation between grand theories as applied to society at large and 
concrete instances of social interaction" (p. 18). This approach, alongside Foucault, allows for examination of the material impacts between documents and realities without assuming a totalizing perspective.

\section{Data Collection}

Data was collected under a Grounded Theory (GT) and Critical Grounded Theory (CGT) approach. Briefly, relevant to my study, GT and $\mathrm{CGT}^{5}$ data collection methods: 1) construct data categories and coding from within the data, rather than through pre-established criteria and 2) allow data collection and analysis to occur simultaneously, and inform each other (Belfrage and Hauf, 2017, p. 260). Professional experience in the agricultural sector ${ }^{6}$ and initial literature review informed data sources, but, as in GT and CGT, the process was in large part inductive (Belfrage and Hauf, 2017, p. 260). Data collection was a two-pronged approach consisting of 61 documents (primary data) and 5, in-depth, semi-structured interviews (secondary data). These interviews were not a representative sample and were thus used under a GT and CGT approach as the "field work" that guided my "desk work" (Belfrage and Hauf, 2017, p. 260). As mentioned above, this simultaneous/cyclical relationship opened new avenues for data sources (as they were revealed in interviews) and interview participants (as they were included in documents).

Documents were initially located using keywords in a Google ${ }^{7}$ search query ${ }^{8}$. Documents were added as they were discovered through, for example, cross-referencing within documents, and recommendations during interviews. Document selection was based on the following criteria: documents must be explicitly created for, or used within, SAWP contexts; documents must have been circulated in Ontario 9 ; the intended audience of the document must (appear to or explicitly) be a SAWP stakeholder; and the document must be "official." For the purposes of this study, "official documents," were considered to be those which SAWP stakeholders would seek out for (what they perceived to be) reliable information on SAWP, related processes and issues,

\footnotetext{
${ }^{5}$ The term CGT is intended to acknowledge that grounded theory rarely claims to be purely inductive in its modern uses (Belfrage \& Hauf, 2017, p. 258). Both theories employ similar data collection techniques.

${ }^{6}$ For many years, I worked in the fields and in packing facilities alongside SAWP workers. In later years, I worked in various administrative roles, with SAWP documents (LMIAs, contracts, work permits), living conditions (inspections, repairs), training and orientation (health and safety, explanation of fees, processes), transportation (to appointments, clinics, work, bunkhouses), communication facilitation (between workers and community members, organizations, and other staff), and English education (writing, reading, and speaking).

${ }^{7}$ As one of the most popular search engines.

${ }^{8}$ Keywords: "health SAWP workers" "SAWP explanation" "SAWP information" "SAWP organizations" "SAWP resources" "SAWP regulations" "SAWP requirements" "SAWP worker things to know" "SAWP" "Seasonal Agricultural Worker Program" "seasonal agricultural workers Canada" "seasonal farm workers Canada" "transportation SAWP" "how does SAWP work" "migrant rights activist groups Ontario".

${ }^{9}$ Analysis concentrated on Ontario for its high concentration of SAWP workers, and accessibility for interviews (as I was located in Ontario).
}

and/or life in Canada. Op-eds, news media, personal blogs, etc. were excluded from the "official documents" criterion.

Document data collection took place from September 25, 2019 to October 25, 2019. A total of 61 English-language ${ }^{10}$ documents of varying lengths (anywhere between 1 and 76 pages) were collected from online sources and by request from relevant stakeholder groups. 68 documents were originally collected and, after initial analysis, seven were excluded from the data set. Reasons include: incompatibility with coding software $(n=4)$, the data source did not meet the collection criteria $(n=2)$, and relevance to SAWP was low $(n=1)$. Documents ranged from SAWP employment contracts to government review of the program, to info-documents on services for SAWP workers, to name a few.

Five, in-depth (30-90 $\mathrm{min})$, semi-structured interviews were conducted between October 20, 2019 and December 5, 2019. Potential participants were identified during literature review, initial search engine queries, by recommendation from stakeholders, and based on well-known organizations within the field. These interviews took place by phone or in-person with civil servants $(n=1)$, farm-owners and collectives $(n=2)$, and community, non-profit, or rights groups $(n=2)$ who have experience with SAWP and communicating about SAWP. Interviews related to participants' (and their organizations') information-sharing networks, practices, experiences, and recommendations; what they communicate about SAWP, to who, and how; what currently works well, and what still requires attention. The workers themselves were not recruited given the risk of research fatigue, the commonly documented fear of repercussions from employers and officials, and the extensive history of worker interviews which creates redundancy in the context of this study. These interviews were the "field work" that guided my "desk work" (Belfrage and Hauf, 2017, p. 260), and were not intended or used as primary data. Given increasing calls to generate research which uplifts, complements, and centers community voices (McLaughlin and Weiler, 2019), these interviews ensured that my data analysis was informed by and remained cognizant of the interests, concerns, and desires of those with lived experience.

\section{Data Analysis}

Documents were coded in nVivo (version 12), first, for descriptive findings and second, for critical implications of these results under a CDA approach. Descriptive findings were crucial in formulating and codifying the scope of SAWP's information barrier, and provided a landscape to begin CDA interpretations within. Further, descriptive findings, which generated specific percentages for each code reference, were useful in quantifying any absences or lacks in documents.

\footnotetext{
${ }^{10}$ SAWP enrollees are from both English-speaking and Spanish-speaking countries. SAWP enrollees from Spanish-speaking countries have varying levels of English literacy. Several documents collected for this study had translations in Spanish (e.g., those distributed by Justicia for Migrant Workers, 2021). The English versions were analyzed within this study.
} 
However, I will focus on CDA results, given the scope of this article.

For clarity, results have been presented in this article as three main analytical themes. As in GT, these themes formed from emerging patterns during the analytic process. First, program representation. This theme refers to how the program is represented and marketed nationally and globally. Existing research (Satzewich, 2007; Vosko, 2018; Binford, 2019) on the subject establishes "successful model of migration management," "economic success," "Canadian-first," "labour shortage solution," and "triple win" as key phrases within public-facing discourse on SAWP. This category primarily establishes the existing landscape of SAWP discourse and confirms previous literature.

Second, stakeholder representation. This theme relates to specific stakeholder mentions. Stakeholder references in the texts belonged to fourteen job categories: F.A.R.M.S., sending country, receiving country, worker, employer, liaison, consulate, NGO or service provider, industry representative, third-party representative, civil servant, workers' family, employers' family, researcher, and settled community. Given an expansive number of stakeholders found in existing research and in my interview data (Preibisch, 2004; Vosko, 2018; McLaughlin et al., 2017; Participant 4, 2019, NGO; Participant 5, 2020, NGO), this stakeholder list is not exhaustive-however, it represents all job identifiers present in these documents after coding. ${ }^{11}$ References to these stakeholders were analyzed according to the depth, frequency, and relative importance given to their mentions within documents. In addition, this theme examines the representation and potential disciplining of relationships and collective responsibility within SAWP landscapes. Collaborative relationships are understood to be key in determining how well, if at all, information is shared.

Stakeholders who are not legally authorized (e.g., in contracts) or government-supported (e.g., through inclusion in program review) are referred to throughout as "non-work" and "unofficial" stakeholders. "Official" stakeholders are the employer, the employee, the sending country, and the receiving country, as determined in the SAWP contract (Government of Canada, 2021), as well as industry associations, labour representatives, and similar, as in some program reviews (Government of Canada, 2019). Non-work and unofficial stakeholders may be NGOs, community members, educators, and so on.

Third, information topics. This theme encompassed twentynine categories related to knowledge subjects. These include, as a few examples, professional communication needs, personal communication needs, workplace health and safety, rights and responsibilities, family and home life, mobility and transportation, enforcement and review, and administrative challenges. Sub-themes were informed by existing literature on key areas of worker safety and wellbeing. Analysis under this

${ }^{11}$ Further illustrating this study's conclusions (i.e., an absence of varied, expansive, and well-rounded stakeholder resources in documents). The implications of this limited list of stakeholders (as it departs from research and personal accounts detailing the vast number of stakeholders involved in SAWP and in enrollees' lives) will be discussed in the results section. category examined the variety, depth, and relative importance of their mentions within texts. Topics were analyzed according to "work" and "non-work themes." Wages and workplace conditions, for example, are considered "work" topics, while family and home life are considered "non-work" topics. These separations are understood to be artificial, but nonetheless prevalent in SAWP discourse (McLaughlin et al., 2017), and thus remain useful in analysis. Given literature on program gaps regarding non-work areas of life (McLaughlin et al., 2017; Caxaj and Cohen, 2018), absences were expected to be key in analysis. In results sections, particular attention is paid to topic omissions, rather than specific discursive phrasing.

\section{RESULTS}

In this section, CDA results for categories program representation, stakeholder representation, and information topics will be presented. Results are particularly significant for their absences, rather than the presence of specific problematic discourse-especially in the case of stakeholder representation and information topics. Initial descriptive analysis (see Figure 1) quantified the absences detailed in the below sections; the percentage of mentions related to labour, industry, and economy concerns overwhelm text related to personal, familial, and community wellbeing. For example, less than $2 \%$ of total references pertained to the personal communication and social needs of workers. CDA results are thus concerned with how absences act within SAWP's discursive spaces to the program's detriment.

\section{Program Representation}

Often, documents avoided normative arguments about SAWP or the viability of its future. For example, documents by a health organization, rather than opening with statements about SAWP, opened with FAQs like "what is the general profile of migrant farm workers?" (Health risks and issues among migrant workers: faqs, 2021a, para. 1). As organizations hope to build more fruitful relationships with other SAWP stakeholders, who often work from differing motivations, navigating value-based discourse on the program may be difficult.

However, where present, overt discourse on the program centers around phrases like "successful model of migration management" or "triple-win", and constructs SAWP as the necessary solution to Canada's labour shortage. Documents typically read, "[SAWP] has proven to be a successful labour mobility program...it is a model of international cooperation that has demonstrated the possibility to maintain an effective and regulated flow of migrant workers..." (Consulado General de México en Toronto, 2016, para. 1). Phrases like “...SAWP...is instrumental in filling [Canada's] critical labour gap...” (Canadian Agricultural Human Resource Council, 2017, p. 6) were also exceedingly common.

Though government-produced documents have recently begun to explicitly acknowledge program flaws (Government of Canada, 2019), the national and international reputation of the program remains strong in many industry contexts and, 


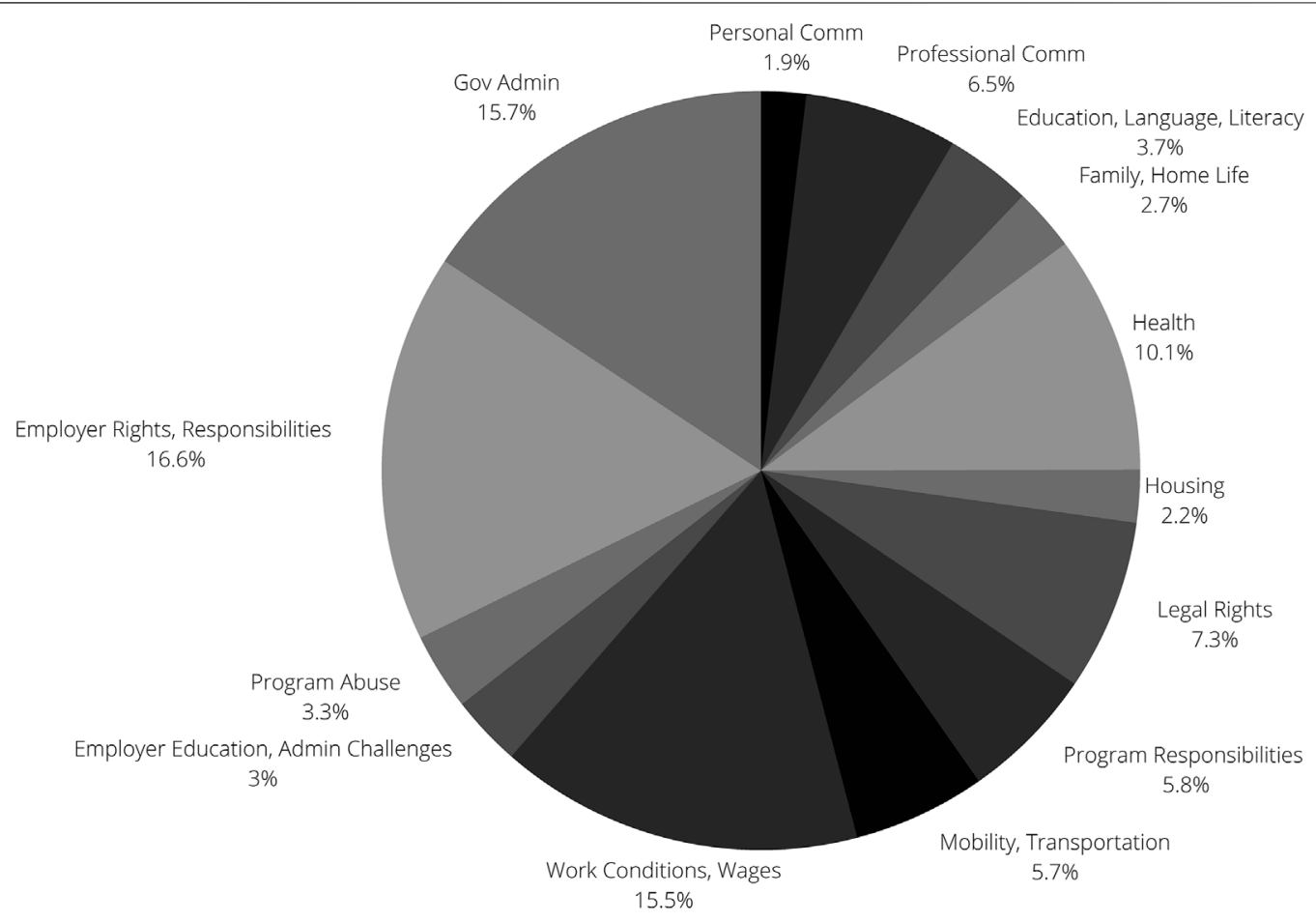

FIGURE 1 | Descriptive results for the Information Topics theme, represented in pie graph format.

importantly, documents did not often challenge SAWP's sustainability as a "labour shortage solution." Notable exceptions include a local migrant rights group which engaged in counter-discourse on the matter: "we need an overhaul of our food systems...we must build communities that prioritize the needs and humanity of migrant farm workers..." (Migrant Rights Network, 2019, para. 6). In addition, interview participants did occasionally speak to the deconstruction of this type of discourse. One participant, reading from their official statement, shared that "an expanded Temporary Foreign Worker Program should at no time... and in no way be viewed as the solution to labour challenges facing Canada's agri-food system" (Participant 2, 2019).

Documents frequently utilized market improvements as a justification for SAWP's continuation. For example, documents stated, "the SAWP benefits the Canadian economy" or "horticulture producers who use the SAWP....are well positioned to help the federal government achieve its budget..." (Canadian Agricultural Human Resource Council, 2017, p. 3-4). However, as above, some documents suggest that economic improvements are not a sufficient marker of success, and downloading labour burdens to under-protected and over-worked populations (Preibisch and Hennebry, 2011; McLaughlin and Hennebry, 2013; Vosko, 2018) is not a sustainable or just solution. Counter-discourse from these documents recognizes that the choice to outsource labour to vulnerable and racialized populations who rely on SAWP indicates the sector is not equipped with well-supported systems in a broader sense.
Overall, analysis of program representation finds that, consistent with existing SAWP literature on neoliberalism within these labour programs (Preibisch and Hennebry, 2011; Binford, 2013; Basok and Bélanger, 2016), documents emphasize economic success over other, more robust indicators of success. In the next two sections, I suggest that the prevalence of these discourses of economization within SAWP documents lays the foundation for the valuing of labour knowledge, roles, and duties over "whole worker" and communal approaches to program participation. The discourse outlined in this section perpetuates the privileging of economic concerns within organizational texts, contributing to gaps in knowledge and program roles, and ultimately participates in channeling behaviours towards narrow economic goals.

\section{Stakeholder Representation}

This section outlines discursive practices surrounding SAWP stakeholders, as present in official documents ${ }^{12}$. Results here pertain to the stakeholder roles, duties, and knowledge included or excluded from program documents, on the understanding that documents participate in valuing, devaluing, aiding, and/or impeding specific stakeholder groups within SAWP spaces through these texts' non-human actions. Communication between stakeholders, mediated by and produced through text, "...control both their own and others'

${ }^{12}$ See Data Analysis section for more information on relevant SAWP stakeholders. 
activity and knowledge..." (Kuhn, 2008, p. 1232) within SAWP spaces.

Broadly, results suggest that documents privilege industry and labour stakeholders, their expertise, input, and resources, over non-work stakeholders. Further, instead of encouraging dialogue and community participation (Giroux, 2009) within program spheres, document references typically excluded the collaborative and community-level approaches that interview participants (e.g., Participant 4, 2019, NGO; Participant 5, 2020, NGO) and local activists (Migrant Workers Alliance for Change, 2019, p. 4) identify as crucial to supporting workers. Specific examples will be discussed below.

First, the variety of stakeholders was limited. Worker, employer, and the receiving country made up well over half of stakeholder mentions within the documents. Mention of unofficial stakeholders was relatively rare. When included, they were typically cursory. For example, on healthcare, analysis often found only brief mentions such as: "...the employer shall take the worker to obtain health coverage in a timely manner" (Government of Canada, 2021, p. 7). Short references like these do not delve deeply into the roles and services of these stakeholders, but rather focus on minimal and bare necessity contact, despite SAWP workers and activists who consistently identify the importance of increasing awareness of and access to routine check-ups, mental health, and general wellbeing health services (Paz Ramirez, 2013; Justicia for Migrant Workers, 2021). Similarly, mentions of stakeholders working in the realm of safer sex, HIV awareness, and related services were absent in all documents examined, despite increased risks in this area (Rapid Response Service, 2013) and anecdotal evidence regarding the need for and benefit of this work (e.g., Participant 4, 2019, NGO). References to education professionals were often limited to basic workplace translation, such as "employers must provide copies of contract in English or French and Spanish" (Government of Canada, 2020b, para. 22). Documents did not include reference to long-term educational opportunities, despite the availability of and desire for educational opportunities tailored to SAWP workers ${ }^{13}$. Fluency, conversational English, educational classes, and professional development were not referenced in documents, despite lower literacy and education levels among some workers (Health risks and issues among migrant workers: faqs, 2021b), and anecdotal evidence to suggest workers desire increased access to these services (Health risks and issues among migrant workers: faqs, 2021a).

As such, discourse around roles and duties do not represent the full range of services unofficial stakeholders provide, can provide, or hope to provide to the program. Stakeholders in these realms have long-established histories of supporting worker needs and contributing to the healthy participation of SAWP enrollees as they attend, not just to their employment needs, but to the wellbeing of "whole workers" both in and out of work. Local groups, religious organizations, non-profit services, teachers, family, friends, and other community leaders play

\footnotetext{
${ }^{13}$ For example, Frontier College in Ontario.
}

pivotal roles in providing well-rounded information to workers in their areas of expertise ${ }^{14}$. These areas include social events, accessing spiritual and religious needs, navigating racist and anti-immigrant sentiments, locating safe transportation, practicing safer sex, advocating for themselves, accessing learning and language initiatives, and coping with isolation and family separation. However, documents rarely addressed their critical roles in any detail.

Here, documents define boundaries as they help decide how stakeholders are conceptualized within SAWP's organizational spaces, the extent of their roles, and the value placed on their range of knowledge. Consistent exclusion of non-work stakeholder groups from official documents minimizes their roles, value, and knowledge within program spaces. As one example, consistent reference to healthcare professionals' roles only insofar as physical and workplace health then structures the authoritative conception of the program-which areas of healthcare are considered acceptable, appropriate, or necessary for SAWP workers to be made aware of, and have access to. Documented lack of awareness around varied and non-work healthcare options (e.g., Participant 4, 2019, NGO; Rapid Response Service, 2013; Justicia for Migrant Workers, 2021) suggests that SAWP texts do participate in directing attention and disciplining actors towards limited physical and workplace health. The impact of this can potentially be felt in the documented prevalence of mental, sexual, and overall wellbeing concerns among SAWP workers (McLaughlin, 2009; Rapid Response Service, 2013; McLaughlin et al., 2017) in more nuanced ways than a focus on "workplace accidents" invokes (Wolkowitz, 2006). ${ }^{15}$

Second, collaboration between community stakeholders, though well-established among these groups (e.g., Participant 4, 2019; see Health risks and issues among migrant workers: faqs, 2021a), were absent in these official documents. The many community support systems, including joint efforts, groups, and events, were not typically documented. Meetings, collective mobile applications, and support sessions were common among the NGOs interviewed, but remain largely unrecorded in official documents. Participants agreed that cross-stakeholder connections were under-documented in any large-scale, regulated, or easily-accessible way (Participant 4, 2019, NGO), making it more difficult to establish and maintain the collaborative information-sharing that they consider essential to their work (Participant 4, 2019, NGO; Participant 5, 2020, NGO). In addition, resource lists, which may facilitate these stakeholder connections, were fairly scarce and outdated. Interview participants (e.g., Participant 4, 2019, NGO; Participant 3, 2019, farm-owner) shared that collaborative work was important to the program, and that they, as program stakeholders, rely on the support and knowledge held within cross-stakeholder connections in several areas of daily program

\footnotetext{
${ }^{14}$ For example, see McLaughlin et al., 2017; Basok et al., 2014; Caxaj \& Cohen, 2019; Vosko, 2018.

${ }^{15}$ Material and bodily impact will be discussed further in Document Agency and Material Impact section.
} 
administration. Participants (e.g., Participant 3, 2019, farmowner) noted that local collaboration and shared knowledge were especially important given the program's unclear program processes (Vosko, 2018) and poor inter-governmental communication (Nakache and Kinoshita, 2010). Increased presence of these collaborative actions at macro-levels would thus improve the ability of stakeholders to share information, build knowledge, and support workers in fuller ways across their life and labour in Canada.

\section{Information Topics}

This section discusses which areas of life and areas of work, relevant to SAWP, are included or excluded from the examined texts ${ }^{16}$. Information topics are understood to be important given that these texts represent the organization as a whole, direct stakeholders' attention, discipline their actions, and link their practices together towards a standard (Kuhn, 2008, p. 1237). In doing so, non-human actors impact which issues, needs, and desires are acceptable, normal, or desirable within SAWP spaces.

As Caropresi ${ }^{17}$ notes, "while work is the main reason why migrant workers are in Canada, around it [are] a series of apparently unrelated needs...that are not usually mentioned or appreciated, perhaps because...they become invisible..." (2013, p. 1-2). Indeed, current activism and writing notes that these needs are not unrelated, as SAWP workers see personal and work spheres intermingling regularly (e.g., McLaughlin et al., $2017)^{18}$. As such, non-work elements are widely understood to be relevant, and crucial, within SAWP spaces, program processes, and information practices. Leaving these non-work elements out of SAWP documents risks exacerbating worker vulnerabilities; many stakeholders are left desiring guidance on navigating these concerns (e.g., Participant 3, 2019, farm-owner), or must handle enrollees' non-work information needs in the absence of any educational documents at a program level (e.g., Participant 4, 2019, NGO).

Within the above context, CDA results demonstrated that SAWP documents continue to maintain boundaries between life and work, which invariably favour the labour side of the dichotomy. Documents typically covered non-work topics with much less detail, nuance, and variety-favoring labour and industry information over subjects related to personal wellbeing through a consistent arranging and displaying (Sheldahl-Thomason, 2018) which grants visibility to labour information and consistently omits other information needs. Some interview participants (e.g., Participant 3, 2019, farmowner) agreed that documents were not a substantial source of information on expectations for navigating workers' personal needs and, further, expressed that the program was negatively affected by the absence of clear information around these

\footnotetext{
${ }^{16}$ See Data Analysis section for examples of relevant information topics.

${ }^{17}$ Caropresi is a former Consulate employee.

${ }^{18}$ For example, workers' access to town centers, socializing and visitors, and other personal activities are mediated by their housing on-farm, and by their reliance on employers for transportation.
}

dynamics (Participant 3, 2019, farm-owner; Participant 4, 2019, NGO).

Absences were perhaps most succinctly and tangibly demonstrated by descriptive analysis results, available in Figure 1 below. These results found that, for example, $15.5 \%$ of references were to workplace conditions and wages, while only $3.7 \%$ references were to language, literacy, education, and translation. Similarly, only $1.9 \%$ references were to personal communication needs (including socialization). Specific examples around these absences will be discussed in more detail below.

As is demonstrated in the coding results from Figure 1, within the documents, work conditions, wages, workplace injuries, employer liabilities, and related labour concerns were mentioned most attentively within documents. For example, whole documents were dedicated to workplace injury claims (e.g., Community Legal Education Ontario, 2009), and whole paragraphs dedicated to "recoverable costs" deducted from workers' pay (e.g., Program related costs, 2021). Documents on the programs' mandate (e.g., General principles for SAWP, 2021) were typically comprised of labour shortage ${ }^{19}$, wage, and hours of work topics, with only occasional and cursory mention to guiding principles like “...workers. . . are to be treated in a fair and equitable manner by the farm employers" (General principles for SAWP, 2021, para. 2).

Overall, then, results suggest that the same attention and care are not paid to social, overall wellbeing, non-labour, and community topics. For example, through avoiding explicit mention of SAWP workers' personal or leisure time, which often occurs on-farm (Paz Ramirez, 2013), documents ignore the realities of SAWP enrollees' living arrangements. Mention of language like "personal," "social" "visitor," "off-work," were scarce or entirely absent from SAWP contracts and documents outlining program requirements (e.g., Government of Canada, 2020b; Government of Canada, 2021). Reference to "personal" (items, expenses, domestic circumstances) were found a total of $\mathrm{n}$ $=8$ times within the 2021 contract. A typical reference to these elements within the contract might look like "the employer may pay the worker in advance so the worker can purchase food and/ or personal items" (Government of Canada, 2021, p. 5). These and similar references did not sufficiently address the above complex concerns regarding personal and leisure time. Recent SAWP reviews (Canadian Agricultural Human Resource Council, 2017; Government of Canada, 2019), as another example, contained no references to terms such as "social," "socialization," "isolation," "community," and similar, as they may pertain to worker needs.

Similarly, healthcare text related to general wellbeing, mental health, sexual health, or healthy lifestyles was much scarcer than their physical and workplace injury counterparts. Only a few documents included discourse such as, "other prominent concerns we have heard from... .workers include...depression" (Justicia for Migrant Workers, 2021, p. 2), or “. . life [for workers] revolves solely around the farm...” (p. 1). Increased and

\footnotetext{
${ }^{19}$ See Program Representation section for more on "labour shortage" discourse.
} 
increasingly-nuanced mentions in this vein would document mental health and social inclusion issues and, importantly, legitimize counter-discourse which rejects the idea that migrants are "just here to work" (Caropresi, 2013; McLaughlin et al., 2017). Non-work transportation, personal mobility, social opportunities, community relationships, and family and home life were similarly absent or lacking. References to family, for example, were largely limited to brief program logistics like, "the government...shall take any or all steps necessary to...pay [outstanding] money... in the case of death of the worker [to] the worker's lawful estate" (Government of Canada, 2021, p. 5) which, again, emphasize economic relations. Discourse which frames familial relations as a significant form of (proactive) worker care (McLaughlin et al., 2017) is notably absent.

Consistent with Program Representation and Stakeholder Representation sections, neoliberal themes structure the inclusion and exclusion of certain information topics, and sustain an uneven privileging of labour and industry information across the frequency, depth, and nuance of document text. On practical terms, these absences place constraints on SAWP stakeholders' ability to access crucial information $^{20}$. Further, under theories of documents' agency, these texts contribute to the constituting of the organization itself through the legitimizing of certain practices over others. A disproportionate focus on labour concerns ${ }^{21}$ within official documents reifies common neoliberal conceptions around the program, many found in Program Representation section, where SAWP enrollees are identified by and related to through their labour alone. Further, it legitimizes the notion that SAWP need not share responsibility for the familial, social, and communal aspects of the program (McLaughlin et al., 2017).

As this standard is solidified within discourse, actions and spaces are disciplined accordingly. Interview participants (e.g., Participant 3, 2019, farm-owner; Participant 4, 2019, NGO; Participant 5, 2019, NGO) and worker accounts (e.g., Justicia for Migrant Workers, 2021) confirm that communication around mental, spiritual, and sexual health, social inclusion, family, and community are often treated as inappropriate and undesirable within the program. For example, Participant 4 (2019), a sexual health worker, spoke to the difficulties in accessing SAWP spaces, the frequent resistance from other stakeholders, and the high rates of SAWP enrollees' with little to no existing information on sexual health topics. Participant 3 (2019, farm-owner) spoke to a personal lack of information on navigating social and community issues with workers. Additionally, this participant spoke to the perception that, within the program, social and leisure time topics were a "bit of a touchy issue" (Participant 3, 2019, farm-owner). Research suggests that SAWP enrollees, in particular, may fear discussing and accessing services related to sexual health (Rapid Response Service, 2013, para. 18), depression, and isolation (McLaughlin et al., 2017).

\footnotetext{
${ }^{20}$ As demonstrated by interview participants (e.g., Participant 4, 2019, NGO; Participant 3, 2019, farm-owner), as well as SAWP enrollee accounts (e.g., Basok et al., 2014; Government of Canada, 2019).

${ }^{21}$ E.g., wages, workplace injuries, work conditions and hours, etc.
}

Under non-human agency theories, this authoritative image of SAWP as a one-dimensional labour program $^{22}$ disciplines stakeholders to align with these boundaries of acceptable communication. We can posit that, for example, the devaluing of social topics within official documents contributes to the above exclusionary behaviours, where stakeholders are uncomfortable, unwilling, or unable to discuss these issues within SAWP spaces. As information-sharing is constricted, important topics remain absent from texts (and other communications), and workers experience continued information barriers. Poor communication on these necessary elements of SAWP impact the wellbeing of workers on real terms. In the above examples, both sexual illness (Rapid Response Service, 2013) and mental illness (Preibisch and Hennebry, 2011; Justicia for Migrant Workers, 2021) have been identified as an increased risk within SAWP communities. The material implications of these discursive absences will be discussed in more detail in Document Agency and Material Impact section.

\section{Resistance Through Information}

Theories on counter-discourse and textual agency suggest stakeholders' own definitions and actions within organizational spaces need not always coincide with official texts, “...in part, because, as part of generating influence over conversation, texts are (re)appropriated and (re)contextualized, such that their influence across practice sites may vary" (Kuhn, 2008, p. 1235). This section discusses tactics community stakeholders employ to actively and creatively engaged in counter-discourse through information. Here, stakeholders can re-define themselves, their roles, and their relationships outside of official discourse (Foucault, 2000; Sheldahl- Thomason, 2018).

Some documents demonstrated positive work to inform enrollees of an expansive spectrum of resources from a vast number of stakeholders. For example, through extensive contact and resource lists ranging from pesticide safety to gender resources, tax explanations, language supports, and contact information ${ }^{23}$. In addition, interview participants spoke to counter-discourse occurring in non-traditional document formats. For example, a group of stakeholders launched a mobile application for the dissemination of flexible, changing ${ }^{24}$ information relevant to SAWP enrollees. Here, relevant information is defined much more limitlessly, and may relate to educational opportunities, social media resources, recreational events, shopping discounts, and more.

Interview data did suggest that much of SAWP's informationsharing network continues to rely heavily on bodily, verbal, and in-person communication. Here, implied and community-based

\footnotetext{
${ }^{22}$ Under a distinct binary between life and labour.

${ }^{23}$ However, many of these resources (especially hyperlinks and contact numbers) were not current. Rather than reflecting an organization's ability to service SAWP workers, these outdated documents may reflect the urgent need for macro-level support in their efforts.

${ }^{24}$ Flexibility in information-sharing is noted to be important by SAWP stakeholders in interview data (e.g., Participant 4, 2019; NGO), and documents (e.g., "Healthcare and insurance for migrant workers: faqs, 2021b; Caropresi, 2013), given the mobility issues and unpredictable working schedules of SAWP workers.
} 
knowledge about SAWP was more evident than in official documents. One participant shared that:

...we go to where the workers are...we'll go to the grocery store and just literally hand out condoms as they're walking off the bus. That way we're reaching a lot of workers at once...(Participant 4, 2019, NGO).

Other interview participants shared similar sentiments regarding their own communicative work. However, overall, document data still demonstrated that information-sharing by these organizations ${ }^{25}$ often provided realistic, transparent, and nuanced information on a much fuller range of concerns.

Documents attempted to mitigate official discourse on the blanket success of the program by providing on-the-ground information, based in research and workers' accounts, on program processes and their extension into personal and nonwork areas of life. For example, "migrant workers are covered under most of the same protections as Canadian farm workers...however, in practice, many workers are unaware of their rights or fear exercising them due to loss of employment, income or work permit" (Background on migrant farm workers in Ontario: faqs, 2021, para. 3). This kind of information may be difficult to engage with, and may contribute to anxieties around the program. For instance, many farm-owners' fear that, among the general public, ". . . growers may be perceived to have ulterior motives..." (Participant 3, 2019, farm-owner). However, when accomplishments and setbacks are shared transparently, and in balance, these honest experiences may encourage collaboration and solidarity as they increasingly shed light on SAWP's structural oppressions. Indeed, some farm-owners are increasingly acknowledging their positionality, in statements like "the system is set up to make it difficult to be anything but exploitive" (Gerber, 2020, para. 10), and "... as much as [we] try to be a respectful and caring employer [s], they still have fear because of the system" (Gerber, 2020, para. 9). Thus, counterdiscourse within program networks has the potential to strengthen bonds between SAWP stakeholders as they "...contest the limits of [their] discursive position [s]" (Sheldahl-Thomason, 2018, p. 131), reject dominant discourse on individualized responsibility, and frame their program participation in mutually beneficial ways.

\section{DISCUSSION}

\section{Neoliberalism and Access to Well-Rounded Information}

The prevalence of neoliberal structures within SAWP spaces is well-established within existing literature (Preibisch and Hennebry, 2011; Binford, 2013; Basok and Bélanger, 2016). These find that SAWP prioritizes economic motivations, measures success by market values, and "de-collectivize [s] employment relationships" (Peck et al., 2015; cited in Preibisch, 2010, p. 423). Several scholars have linked these and

\footnotetext{
${ }^{25}$ For example: Justicia for Migrant Workers, Healthcare and insurance for migrant workers: faqs, 2021b, Migrant Workers Alliance for Change.
}

other factors to the creation of disposable and precarious workforces. For example, Preibisch situates Canada's agricultural work programs within a "commitment to a neoliberal ideology" which "erode [s] social protections" (2020, p. 423) and ultimately "import [s] workers, not people" (2010, p. 432). When we expand these arguments to examine how neoliberal values affect other aspects of the program, as they relate to information-sharing, we see an extension of neoliberalism into SAWP's knowledge landscape. Important non-work stakeholders and information topics are obscured and de-emphasized as they, too, are caught up in these processes.

Stakeholder Representation Section found similar decollectivizing of employment relationships, as both specific text and broader communication tools (e.g., contact lists, databases, forums, etc.) related to communal work were lacking. Instead, weak communication bonds across at least some stakeholder groups (Nakache and Kinoshita, 2010; Participant 4, 2019, NGO; Participant 3, 2019, farm-owner) were perpetuated by official documents through key absences. These stakeholders are wellestablished as essential to worker wellbeing (Preibisch, 2004; McLaughlin et al., 2017; Vosko, 2018), and their lack of inclusion in official documents threatens to obscure and discursively discourage their input. Documents simultaneously reflect increased worker self-reliance, and decreased inclusion of stakeholders who address social problems-mental health workers, sexual health workers, community leaders, and so on. Stakeholders who align more closely with market value (i.e., labour and industry stakeholders) are given most attention, nuance, and relative importance when recording their roles and program input.

Information Topics Section demonstrated a similar privileging of market values over social needs. This is potentially related to the de-collectivizing of employment relationships in Stakeholder Representation section, if we understand SAWP as a networked phenomenon which relies on collaboration to share and build well-rounded knowledge (Participant 3, 2019, farm-owner; Participant 4, 2019, NGO). Recalling results under this theme, selective information-sharing rendered social, familial, and community topics largely invisible, while industry and labour subjects received significant detail and nuance. Employer and employee program expectations (22.4\%), and workplace conditions and wages (15.5\%), for example, dominated SAWP's discursive spaces.

These failures in information-sharing are particularly significant when we understand them within continuums of harm, coercion, and unfree labour (Thomas et al., 2016; Strauss and McGrath, 2017). As has been argued throughout, labour and life are inextricably intertwined (McLaughlin et al., 2017), the social, familial, and communal are vitally important, and under current ideologies, these dimensions are fatally underserved within SAWP populations (Preibisch, 2010; Horgan and Liinamaa, 2012). Workers experience subpar conditions related to their familial wellbeing (McLaughlin et al., 2017), mental health (Justicia for Migrant Workers, 2021), personal mobility (Paz Ramirez, 2013), social autonomy (Horgan and Liinamaa, 2012; Paz Ramirez, 2013), among other areas of life. The invisibility of these needs within documents risks 
perpetuating notions that SAWP workers should not have, or do not need, non-work relationships, lives, and fulfillment (Participant 4, 2019, NGO). This has implications for workers' ability to express themselves as "whole workers," to discuss their needs, and access these services, and is potentially linked to these increased risks to their overall wellbeing (Horgan and Liinamaa, 2012; Rapid Response Service, 2013; McLaughlin et al., 2017).

Instead, as seen in Resistance Through Information section, documents can hold information, resources, and tools related to these various harms noted in literature, and to self-advocacy against them. In this way, access to information is conceptualized in this study as a right, "a fundamental need" (Caropresi, 2013, p.2) in knowing, feeling, and doing in the world, with interrelated impacts on other aspects of life.

\section{Document Agency and Material Impact}

This section will touch more on the material and bodily consequences of incomplete or inadequate documents. In this section, I agree with current research which argues that inattention to the fullness of SAWP workers existences and needs co-constitutes "workers, not people" (Preibisch, 2010, p. 432). Within the information-sharing context, this refers to a consistent omission of important, non-work information ${ }^{26}$, which fails to communicate value or attend to needs beyond workers' labour.

As discussed in Information Topics section, documents participate in activities like defining boundaries, representing organizational values, directing attention, and disciplining actors. As one example of these impacts, Participant 4 (NGO, sexual health, 2019) recounted an experience during a local information fair:

... [we were told that] if we want community members to be on board with welcoming the workers

...we don't want the community thinking that they're

...just here to have sex with everybody, and [so, when they turned down our involvement] we were like, "um, ok" (Participant 4, 2019, NGO).

Here, stakeholders internalized notions around (un)acceptable behaviour exhibited by SAWP workers. Healthy social interactions, under this discourse, are reframed as antithetical to their success within the program. Instead, SAWP enrollees are expected to invoke imagery of the hardworking labourer, even in their personal time ${ }^{27}$.

Social, non-work needs may thus be increasingly silenced as stakeholders define their roles within program spaces according to neoliberal values. These disciplinary techniques may have significant consequences for worker wellbeing. Here, we might

\footnotetext{
${ }^{26}$ Well-documented as relevant to the program (McLaughlin et al., 2017; Caxaj \& Cohen, 2019; Caropresi, 2013; Justicia for Migrant Workers, 2021; Participant 4, 2019, NGO; Participant 3, 2019, farm-owner).

${ }^{27}$ More analysis of bodily action (e.g., as in Paz Ramirez, 2013) and of personal accounts (e.g., as in interview data) would solidify and deepen discussion of particular moments of disciplinary and self-disciplinary action.
}

take a specific example. Results found a complete lack of mentions related to safer sex and similar topics, as well as extremely limited mentions regarding socialization and social wellbeing. Research and advocacy have highlighted complex concerns in these areas. For example, severe isolation (Horgan and Liinamaa, 2012), depression and loneliness (McLaughlin et al., 2017), as well as an increased risk of HIV among workers (Rapid Response Service, 2013). This has this been explicitly linked to lack of awareness and information on practical terms (Rapid Response Service, 2013, para. 9-17). In addition, on several other information topics, absences identified here correspond with existing and longstanding calls for increased supports to combat ongoing program failures. For example, community belonging ${ }^{28}$ (Justicia for Migrant Workers, 2021), legal rights (Participant 2, 2019, NGO), and educational tools (Justicia for Migrant Workers, 2021). Limited mentions to safe transportation options for workers within documents (see Figure 1) can be examined within a context of frequent vehicular accidents among SAWP workers (CBC News, 2012, February 6; Saylors, 2019, July 19; Simon, 2016, September 5; Wilhelm, 2013, May 6). In each of these areas, documents potentially contribute to the exclusion of these topics and needs from the authoritative understanding of the program through similar processes.

In considering embodiment, we can ask what attention to SAWP bodies only insofar as productivity, labour skill, and workplace accidents means for worker wellbeing. Not only does this approach ignore the social, emotional, and collective experiences of labouring bodies (Wolkowitz, 2006; McLaughlin et al., 2017; Paz Ramirez, 2013), it also avoids program responsibility for these bodies' wellbeing at structural levels (Wolkowitz, 2006, p. 114) ${ }^{29}$. For example, we can consider the impact of a mind-body binary (p. 174) within SAWP, which divorces stress, isolation, and depression concerns from the healthy working body ${ }^{30}$. We can consider the consequences of an understanding of the body which is disconnected from networks of community, so that it is no longer considered a “...social body, but naturalised... as the merely 'physical"” (Wolkowitz, 2006, p. 175). In this way, we can ask what SAWP's current construction of the body (Wolkowitz, 2006) is missing, particularly as constructed through these documents, and with what consequences for worker health, safety, and subjectivities.

Notably, under non-human agency theories, we can also ask what an ethical and relational engagement with SAWP knowledge would look like, and consider such a relationship's impact on what is documented, how, and with which intentions. This will be discussed in more detail in the following section.

\footnotetext{
${ }^{28}$ Including anti-racism supports.

${ }^{29}$ For example, by ignoring the structural and long-term factors underpinning socalled accidents (Wolkowitz, 2006, p. 114) but also by upholding the notion that social, emotional, and communal needs are beyond the scope of SAWP (Paz Ramirez, 2013; Basok et al., 2014; McLaughlin et al., 2017; Justicia for Migrant Workers, 2021).

${ }^{30}$ Despite the fact that these emotional experiences carry interconnected physical experiences and symptoms with them (Wolkowitz, 2006, p. 174).
} 


\section{Theoretical Implications}

The main theoretical implications of this study's results are, first, to suggest information-sharing as an important practice of labour in embodied and emotional ways. Embodied labour is often discussed around the physical field and farm work of SAWP enrollees (Perry, 2018; Perry, 2019), but not often, as yet, with regards to knowledge practices occurring within program spaces. The second goal is to extend theories on non-human agency ${ }^{31}$ to realms of SAWP and information-sharing studies. These theories pre-suppose non-human agency and, importantly, understand the relation between human and non-human agents to be "working with rather than working on" (Pettinger, 2015, p. 284).

First, results demonstrated that information-sharing was a significant labour, particularly in SAWP contexts. Stakeholders spent substantial time and effort understanding, fulfilling, and troubleshooting information needs, especially in the face of heavy information failures (Nakache and Kinoshita, 2010; Paz Ramirez, 2013; Caxaj \& Cohen, 2019). Though information is in many ways immaterial (Elden and Crampton, 2007), there were distinctly embodied, personal, and emotional dimensions to this work, as has been theorized regarding other forms of labour (Wolkowitz, 2006; Paz Ramirez, 2013; Pettinger, 2015; Perry, 2019). Interview participants attest to the emotional and bodily aspects of this labour, standing in parking lots all evening (Participant 4, 2019, NGO), or experiencing the frustrations and joys of the work (Participant 4, 2019, NGO; Participant 5, 2020, NGO). Similarly, document text produced by NGOs demonstrated significant care and effort in implementing information-sharing practices which were grounded in real experience and labour in their fields. For example:

Many migrants are outside the reach of. . .typical methods of communication and promotions. . .To be effective, promotional efforts should target the areas which workers frequent or partner with organizations with well established channels of accessible communication for the workers (Health risks and issues among migrant workers: faqs, 2021b, para. 8).

Excerpts like these, additionally, point to the collectiveness of this knowledge labour. Stakeholders pass good practices amongst each other-one's which, not only conform to SAWP's organizational expectations, but, more importantly, achieve the safest and most successful outcome for workers (Wolkowitz, 2006).

Though not included in this study, interviews with SAWP enrollees might demonstrate that, similarly, information labour is a significant aspect of their program work-especially given the information barriers and inaccuracies outlined in results here, and in literature (Nakache and Kinoshita, 2010; Paz Ramirez, 2013; Caxaj and Cohen, 2019). In this way, framing knowledgesharing as a labour process gives increased attention to its weight

\footnotetext{
${ }^{31}$ This study has relied primarily on Foucauldian thought for analysis of document agents, given the relevance of disciplinary techniques. However, there are numerous theories on non-human agency (e.g., in performance studies, see Pettinger, 2015; in new materialism and Indigenous theories, see Rosiek et al., 2019). Some of these are explored here, in addition to Foucauldian theories, particularly for their explicit writings on ethical and responsible relations to nonhuman agents.
}

within program spheres. Here, information is not just a thing produced, but an inextricable part of the bodies, materials, and relations that hold them. Understanding knowledge as labour, as a process, and not just as objects, does justice to the role this labour has in their program lives, and provides an avenue for critical analysis of where these relations create tension, need support, and so on.

Importantly, activist efforts demonstrated that informationsharing practices are a potential avenue for embodied resistance. For example, the efforts of community stakeholders to collect and share information which protects worker bodies (Wolkowitz, 2006, p. 63), or the importance of physicality to stakeholders' labour with workers, even in emotional or social roles (p. 2) demonstrates the persistently embodied aspects of informationbased resistance. Stakeholders "...carve out a space for themselves that allows some degree of control..." (p. 32) through the creation of small moments of "play as [a form] of resistance," (Wolkowitz, 2006, p.16, p.16) ${ }^{32}$, the reappropriating of official texts, and the carrying of innovative and subversive knowledge within their bodies ${ }^{33}$.

Second, and relatedly, theories on non-human agency can be extended to the study of documents as a means to apply relational and ethical perspectives to our work with documents, communicative tools, and knowledge. Within this study, agency can be seen, for example, in the way information moves across context, time, and place. Document data found acting within the program was produced in the United States (e.g., California Division of Occupational Safety and Health, 2011), was produced over a decade earlier (e.g., Occupational Safety and Health Administration, 2005), was produced for nonagri-food sectors (e.g., U.S. Department of Health and Human Services, 2001), and so on. Yet, these pieces of information were active within current SAWP spaces, indicating their ongoing, new, or changed importance within SAWP spaces. Here, then, documents are able to move, act, and impact beyond their initial production (Foucault, 2000; Sheldahl-Thomason, 2018). In particular, creative work with unexpected ${ }^{34}$ documents in the face of information failures are illustrative of, not only the agency of these non-human materials, but the relationality of that agency. Stakeholders have interpreted, adapted, and reimagined documents which were not originally intended for SAWP contexts to combat lack of information. Here, the necessity to co-create knowledge-to interact with texts and shape knowledge expression alongside them-to address information needs indicates the potential for what performance studies has called "working with rather than working on" (Pettinger, 2015, p. 284). Stakeholders are not using static texts, but are engaging with them for their

\footnotetext{
${ }^{32}$ For example, Participant 4 (2019, NGO) shared that an important aspect of the work is seizing small opportunities to connect with workers, create moments of carefree expression, and release stress and tension from their bodies.

${ }^{33}$ See Limitations and Areas for Future Research section for more on bodily records of knowledge.

${ }^{34}$ Unexpected, here, refers to these out-of-context, out-of-date, out-of-location, etc. documents described above.
} 
possibilities, and the interconnected knowledge they bring together.

Non-human agency theories understand that, while we must document worker selves, lives, needs, and desires accurately, we must also consider the future possibilities we open up when we engage with information and information materials. This necessitates moments of intention and responsibility in relations with materials, and a focus on situated instances where there is an ethical responsibility within these relationships. In the case of SAWP information, a responsibility to relate to information and its tools, giving them proper significance, and to collaborate with them towards an ethical information-sharing practice-in what we choose to impart on documents, what they choose to impart on us, and what this means for the realities we then co-create. Recalling the example of sexual health (see Document Agency and Material Impact section), we see these specific, situated examples where documents exercise their ability to act and impact, and these theories of non-human agency allow critical examination of how relational and ethical engagement with knowledge can be achieved, in that moment, towards enabling spaces we hope to see.

These approaches are complementary to current SAWP research interested in illuminating interconnected and networked processes, and in expanding our understanding of relevant agents within program spaces (Horgan and Liinamaa, 2012; McLaughlin et al., 2017; Vosko, 2018). The implications of non-human agency can be deepened in future research, and my results are an initial indication that they may be useful-particularly in their emphasis of networks, and their possibilities for fostering ethical relations which, in this context, implies a shared responsibility towards good knowledge-sharing alongside non-human materials, towards the bettering of SAWP workers' experiences.

\section{Practical Implications}

Recommendations for practice and advocacy largely pertain to uplifting current work, and echo sentiments shared by experienced stakeholders in interview settings. Recommendations here share the sentiment that advocacy regarding SAWP should involve the continuation of the program (as a vital source of livelihood) without disregarding the many and varied areas which require improvement (Silverman and Hari, 2016, p. 92).

Results demonstrated poor documentation of networks and collective work that foster shared responsibility. Related to this, there was poor documentation of the non-work information topics held within these stakeholders and stakeholder relationships. As interview participants shared:

I think that there are a lot of really great people doing frontline work. . .that we don't hear about. . .it seems like everyone's doing great work, but they're all kind of doing it individually, and then once a year we come together. . .but once a year isn't really that much. It would be nice to have something that was ongoing" (Participant 4, 2019, NGO).

Interview participants suggested that these aims could be met through the development of national online forums for resource gathering and professional networking (Participant 4, 2019, NGO), or through the increased prevalence of mobile applications and similar projects (Participant 5, 2020, NGO).

In terms of subject areas, my results, previous research, and personal accounts suggest that SAWP can still benefit from increased attention to non-work aspects of the program, and the acknowledgement that these are not inherently separate from labour concerns. These areas relate to, but are never limited to, social life, belonging, family and community ties, personal mobility and transportation, educational opportunities, sexual health, spiritual health, and mental health. To that end, increased structural and governmental support for the sharing of current, transparent, and in-practice information is needed. Further, while stakeholders engage in creative information-gathering, increased documents created and circulated specifically with SAWP in mind may be helpful. Indeed, Caropresi, working in the realm of information-sharing, notes that the tailored production of information materials was of marked interest to farm-owners, as "... some of them have stated...their desire to learn more about the subject. . to adapt or create...materials for migrant workers. ." to better fulfill their specific needs (2013, p. 3). Many documents contained information specific to other countries, or relating to migrant workers more broadly, so their applicability to SAWP enrollees may vary depending on the context. Documents which address the experiences of SAWP workers as a distinct group may be beneficial to education, awareness, solidarity, feeling heard, and feeling prepared.

The data for this study demonstrated that information represents a shared need among all stakeholders. Documents contained potentially useful information for a variety of program agents-and interviews illuminated the possibilities for deepening this information network. All interview participants expressed that they rely on information at one point or another in fulfilling their roles. When considered from a networked perspective, information-sharing can represent a meeting place, within documents, where workers can "contest the limits of their discursive positions" (Sheldahl-Thomason, 2018, p. 131) as disposable, labouring bodies. Further, stakeholders note the collaborative possibility to "include what [each] party need [s]" (CBC News, 2013, april 3) and improve common ground among stakeholders. As SAWP literature has demonstrated (Basok et al., 2014; Cohen and Caxaj, 2019; McLaughlin et al., 2017; Vosko, 2018), the well-being of SAWP enrollees encompasses a multitude of interconnected and inseparable issues (health, employment, socialization, education, etc.). As such, stakeholders across these areas are inherently related, and are most effective when working collaboratively.

\section{Limitations and Areas for Future Research}

This study did not examine verbal and bodily communication (i.e., "bodies-as-texts," see Chávez, 2009), Spanish-language documents, or the heterogeneity of racialized and gendered experiences within information barriers. Interview data demonstrated a persistence of verbal and bodily communication within SAWP spaces, particularly given literacy levels, access issues ("Health and insurance," n.d., para. 8), and related barriers. Additional research here would 
be extremely beneficial. Work on "bodies-as-texts" (Chávez, 2009) may illuminate processes through which bodies act as their own documentation of knowledge. This is a potential avenue for further exploring embodied resistance. Though many documents were English-Spanish translations, there are potential nuances in Spanish-language texts which would provide additional insights. Lastly, studies on the way (differing) racialized and gendered identities intersect with information barriers and information-gathering processes would add important nuance to these discussions.

\section{CONCLUSION}

This study has focused on discursive practices within the Seasonal Agricultural Worker Program (SAWP), with implications for the creation and sustaining of disposable, labouring bodies under neoliberalism, and for the practical improvement of informationsharing practices within program spaces. I have argued that, alongside other disciplinary techniques (Preibisch, 2010; Braun, 2012; Paz Ramirez, 2013; Basok et al., 2014), discursive practices contribute to the creation and sustaining of "workers, not people" (Preibisch, 2010, p. 432) through the discipline and control of (ab)normal communicative practices. First, labour and industry stakeholders, and their input into program spaces, are given relative importance within documents, through the frequency, nuance, and detail given to their mentions. Non-work stakeholders' roles, though crucial, are not documented to communicate their significance. Second, labour and industry information are given overwhelming priority within SAWP's official documents. Significant absences were noted across social, familial, and community wellbeing, which impact workers' valuation and self-expression as "whole workers."

In resistance to this, community stakeholders are engaging in "radical writing" (Sheldahl- Thomason, 2018), a task of "...painstakingly restructur [ing]a discourse from within..." (Sheldahl-Thomason, 2019, p. 235), as they use their own methods to document important non-work agents and information. Mobile applications, websites, and crossstakeholder networks give visibility to the social, economic, communal, emotional, and cultural needs of SAWP enrollees,

\section{REFERENCES}

Agri-Food Economic Systems. (2015, April 5). The Economic Impact of the Seasonal Agricultural Worker Program in the Ontario Horticulture Sector. Foreign Agricultural Resource Management System. Available at: https://cahrc-ccrha.ca/programs/emerging-agriworkforce-issues/ reports

Background on migrant farm workers in Ontario: faqs (2021). Migrant Worker Health. Available at: http://www.migrantworkerhealth.ca/ BackgroundWorkers.html

Basok, T., and Bélanger, D. (2016). Migration Management, Disciplinary Power, and Performances of Subjectivity: Agricultural Migrant Workers' in Ontario. Can. J. Soc. 41 (2), 139-164. doi:10.29173/cjs22284

Basok, T., Bélanger, D., and Rivas, E. (2014). Reproducing Deportability: Migrant Agricultural Workers in South-Western Ontario. J. Ethnic Migration Stud. 40 (9), 1394-1413. doi:10.1080/1369183X.2013.849566 and to the networks of support that work to meet them. In this way, information-sharing represents a collaborative need among all stakeholders (Participant 3, 2019, farm-owner; Participant 4, 2019, NGO; Caropresi, 2013), and may open up new possibilities for communal responsibility which resists neoliberalism's individualizing ideologies. To this end, I have suggested that learning to relate to documents as non-human agents may foster ethical and relational interactions between all program agents, as we consider what "good documents" and "good information" may contribute to the program's future possibilities, and we continue the task of "painstakingly restructuring" SAWP spaces.

\section{DATA AVAILABILITY STATEMENT}

The raw data supporting the conclusions of this article will be made available by the authors, without undue reservation.

\section{ETHICS STATEMENT}

The studies involving human participants were reviewed and approved by the Carleton University Research Ethics Board. The patients/participants provided their written informed consent to participate in this study.

\section{AUTHOR CONTRIBUTIONS}

The author confirms being the sole contributor of this work and has approved it for publication.

\section{ACKNOWLEDGMENTS}

This article is based on my thesis research conducted with the School of Communication and Journalism, Department of Communication and Media Studies, at Carleton University. Thank you to Dr. Irena Knezevic, and the rest of my thesis committee for their help in completing this work.

Bauder, H. (2008). Foreign Farm Workers in Ontario (Canada): Exclusionary Discourse in the Newsprint media. J. Peasant Stud. 35 (1), 100-118. doi:10.1080/03066150801983287

Belfrage, C., and Hauf, F. (2017). The Gentle Art of Retroduction: Critical Realism, Cultural Political Economy and Critical Grounded Theory. Organ. Stud. 38 (2), 251-271. doi:10.1177/0170840616663239

Bennett, S. (2018). Constructions of Migrant Integration in British Public Discourse: Becoming British. London, UK: Bloomsbury Academic.

Binford, A. L. (2019). Assessing Temporary Foreign Worker Programs through the Prism of Canada's Seasonal Agricultural Worker Program: Can They Be Reformed or Should They Be Eliminated. Dialect Anthropol. 43 (4), 347-366. doi:10.1007/s10624-019-09553-6

Binford, L. (2013). Tomorrow We're All Going to the Harvest Temporary Foreign Worker Programs and Neoliberal Political Economy. 1st ed. Austin: University of Texas Press.

Braun, J. (2012). Respectable Subjects: The Commonwealth Caribbean Seasonal Agricultural Workers Program in Postcolonial Context (MR93634. ProQuest Dissertations: [Doctoral Dissertation, Carleton University. 
Brown, W. (2015). Undoing the Demos: Neoliberalism's Stealth Revolution. New York: Zone Books.

Butler, J. (1990). Gender Trouble: Feminism and the Subversion of Identity. Abingdon: Routledge.

California Division of Occupational Safety and Health. (2011). A Heat Safety Fact sheet." California Division of Occupational Safety and Health. Available at: http://www.migrantworkerhealth.ca/Resources.html

Canadian Agricultural Human Resources Council. (2017). A Review of Canada's Seasonal Agriculture Worker Program. Canadian Agricultural Human Resources Council, December. Available at: https://cahrc-ccrha.ca/sites/ default/files/Emerging-IssuesResearch/A\%20Review\%20of\%20Canada $\% 27 \mathrm{~s} \%$ 20SAWP-Final.pdf

Canadian Agricultural Human Resources Council. (2019). Ontario Report. Canadian Agricultural Human Resources Council. Available at: https:// cahrc-ccrha.ca/programs/agrilmi/provincial-data/ontario

Caropresi, M. (2013). Communication a Tool for Better Safety, Compliance and Understanding of Migrant Workers. Atoctli Magazine. Available at: https:// www.casa-acsa.ca/wp-content/uploads/2013-00_Communication_Tool_for_ Farmers_Migrant_Workers.pdf

Caxaj, C., and Cohen, A. (2018). Bodies and Borders: Migrant Women Farmworkers and the Struggle for Sexual and Reproductive justice in British Columbia, Canada. Alternate Routes 29, 90-117.

Caxaj, C. S., and Cohen, A. (2019). "I Will Not Leave My Body Here": Migrant Farmworkers' Health and Safety amidst a Climate of Coercion. Ijerph 16 (15), 2643-2656. doi:10.3390/ijerph16152643

CBC News. (2013). Magazine Targets Needs of Migrant Workers. CBC News, April 3. Available at: https://www.cbc.ca/news/canada/windsor/magazinetargets-needs-of-migrant-workers- 1.1365567

CBC News. (2012). Ontario Crash Kills 11, Including Migrant Workers. CBC News, February 6. Available at: https://www.cbc.ca/news/canada/ontariocrash-kills-11-including-migrantworkers-1.1159929

Chávez, K. R. (2009). Embodied Translation: Dominant Discourse and Communication with Migrant Bodies-As-Text. Howard J. Commun. 20 (1), 18-36. doi:10.1080/10646170802664912

Cheng, H. (2016). On Migrant Workers' Social Status in Taiwan: A Critical Analysis of Mainstream News Discourse. Int. J. Commun., 2509-2516.

Community Legal Education Ontario. (2009). Worker's Compensation: Making a Claim. Community Legal Education Ontario, February. Available at: http://www.migrantworkerhealth.ca/Resources.html

Consulado General de México en Toronto. (2016). Seasonal agricultural workers program." Consulado General de México en Toronto, June 3. Available at: https://consulmex.sre.gob.mx/toronto/index.php/en/swap

Cooren, F. (2004). Textual agency: How Texts Do Things in Organizational Settings. Organization $11 \quad$ (3), 373-393. doi:10.1177/ $13505084040199810.1177 / 1350508404041998$

Elden, S., and Crampton, J. W. (2007). Space, Knowledge and Power: Foucault and Geography. illustrated ed. Aldershot, England: Ashgate. doi:10.4324/ 9781315610146Space, Knowledge and Power

Fairclough, N. (2000). Language and Neo-Liberalism. Discourse Soc. 11 (2), 147-148. doi:10.1177/0957926500011002001

Fairclough, N. (2014). Language and Power. 3rd ed. London, United Kingdom: Routledge.

Foucault, M. (2000). "Lives of Infamous Men," in Power: Essential Works of Michel Foucault. . Editor J D. Faubion (R. Hurley, Trans.New York: The New Press), 3, 1954-1984.

Foucault, M. (1995). "Panopticism," in Discipline \& Punish: The Birth of the Prison. Editor A. Sheridan (Trans: Vintage Books), 195-228.

Franck, A., and Anderson, J. (2019). The Cost of Legality: Navigating Labour Mobility and Exploitation in Malaysia. Int. Q. Asian Stud. 50 (1), 19-38.

General principles for SAWP (2021). Foreign Agricultural Resource Management Service. Available at: https://farmsontario.ca/things-toknow/general-principles-for-sawp/

Gerber, L. (2020). If Canadian Consumers “Knew the Work, They'd Value the workers." the Record, June 15. Available at: https://www.therecord.com/ news/waterloo-region/2020/06/15/if-canadian-consumers-knew-thework-theyd-value-the-workers.html
Giroux, H. A. (2009). Hard Lessons: Neoliberalism, Education, and the Politics of Disposability. Pol. Futures Edu. 7 (5), 570-573. doi:10.2304/ pfie.2009.7.5.570

Government of Canada. (2021). Contract for the Employment in Canada of Seasonal Agricultural Workers from Mexico - 2021. Government of Canada. Available at: https://www.canada.ca/en/employment-socialdevelopment/services/foreign-workers/agricultural/seasonalagricultural/apply/mexico.html\#h2.2

Government of Canada. (2020a). Hire a Temporary Worker through the Seasonal Agricultural Worker Program - Overview. Government of Canada, July 12. Available at: https://www.canada.ca/en/employment-social-development/ services/foreignworkers/agricultural/seasonal-agricultural.html

Government of Canada. (2020b). Hire a Temporary Worker through the Seasonal Agricultural Worker Program - Program Requirements. Government of Canada, July 12. Available at: https://www.canada.ca/en/employment-socialdevelopment/services/foreign-workers/agricultural/seasonal-agricultural/ requirements.html

Government of Canada. (2019). Primary Agriculture Review - what We Heard. Government of Canada, February 12. Available at: https://www.canada.ca/en/ employment-socialdevelopment/services/foreign-workers/reports/primaryagriculture.html

Health risks and issues among migrant workers: faqs (2021a). Migrant Worker Health. Available at: www.migrantworkerhealth.ca/HealthRisks.html

Healthcare and insurance for migrant workers: faqs (2021b). Migrant Worker Health. Available at: http://www.migrantworkerhealth.ca/HealthcareGeneral. html

Horgan, M., and Liinamaa, S. (2012). Double Precarity: Experiences of Former Seasonal Agricultural Workers Who Settle in Rural Nova Scotia. Halifax, N.S: Atlantic Metropolis Centre.

Justicia for Migrant Workers. (2021). The Seasonal Agricultural Worker Program. Justicia for Migrant Workers. Available at: http://www. justicia4migrantworkers.org/bc/pdf/sawp.pdf

Knezevic, I. (2011). Food, Discourse, and Democracy: European union's Enlargement and Food Policy in the Western Balkans (NR88672) [Doctoral Dissertation. Ontario: York UniversityProQuest Dissertations.

Kuhn, T. (2008). A Communicative Theory of the Firm: Developing an Alternative Perspective on Intra-organizational Power and Stakeholder Relationships. Organ. Stud. 29 (8-9), 1227-1254. doi:10.1177/0170840608094778

MacLean, D., and McLaughlin, J. (2018). Migrant Farm Workers and the Cruel Trade-Off at Your Local Produce Aisle. MacLean's, January 18. Available at: https://www.macleans.ca/news/canada/migrant-farm-workers-and-the-crueltrade-off-at-your-localproduce-aisle/

McLaughlin, J., and Hennebry, J. (2013). "Pathways to Precarity: Structural Vulnerabilities and Lived Consequences for Migrant Farmworkers in Canada," in Producing and Negotiating Non-citizenship: Precarious Legal Status in Canada. Editors L. Goldring and P. Landolt (Toronto: University of Toronto Press), 175-194.

McLaughlin, J. (2009). Migration and Health: Implications for Development: A Case Study of Mexican and Jamaican Migrants in Canada's Seasonal Agricultural Workers Program. Ottawa, Ontario: FOCUS.

McLaughlin, J., Wells, D., Mendiburo, A. D., Lyn, A., and Vasilevska, B. (2017). 'Temporary Workers', Temporary Fathers: Transnational Family Impacts of Canada's Seasonal Agricultural Worker Program. ri 72 (4), 682-709. doi:10.7202/1043172ar

Meyer, M., and Wodak, R. (2001). Methods of Critical Discourse Analysis. London: SAGE.

Migrant Rights Network. (2019). Platform. Migrant Rights Network. Available at: https://migrantrights.ca/about/platform/

Migrant Workers Alliance for Change. (2019). Migrant Worker Policy Priorities. Migrant Workers Alliance for Change, May. Available at: https:// migrantworkersalliance.org/category/reports/farmworkers/

Mysyk, A., England, M., and Arturo, A. G. (2009). A Case for Certified Interpreters for Participants in the Canada/Mexico Seasonal Agricultural Workers Program. Hum. Organ. 68 (3), 318-327. doi:10.17730/humo.68.3.6g012756050r04h8

Nakache, D., and Kinoshita, P. J. (2010). The Canadian Temporary Foreign Worker Program: Do Short-Term Economic Needs Prevail over Human Rights Concerns. IRPP Study 5, 1-58. 
Occupational Safety and Health Administration. (2005). OSHA Fact Sheet. Occupational Safety and Health Administration, September. Available at: http://www.migrantworkerhealth.ca/Resources.html

Paz Ramirez, A. B. (2013). Embodying and Resisting Labour Apartheid: Racism and Mexican Farm Workers in Canada's Seasonal Agricultural Workers Program. Vancouver, BC: [Master's Thesis, University of British Columbia. ProQuest Dissertations. doi:10.14288/1.0103384

Perry, J. A. (2019). Images of Work, Images of defiance: Engaging Migrant Farm Worker Voice through Community-Based Arts. Agric. Hum. Values 36 (3), 627-640. doi:10.1007/s10460-018-9861-9

Perry, J. A. (2018). Play-making with Migrant Farm Workers in Ontario, Canada: A Kinesthetic and Embodied Approach to Qualitative Research. Qual. Res. 18 (6), 689-705. doi:10.1177/1468794117743463

Pettinger, L. (2015). Embodied Labour in Music Work. Br. J. Sociol. 66 (2), 282-300. doi:10.1111/1468-4446.12123

Preibisch, K., and Hennebry, J. (2011). Temporary Migration, Chronic Effects: The Health of International Migrant Workers in Canada. Canadian Medical Association. Journal 183 (9), 1033-1038. doi:10.1503/cmaj.090736

Preibisch, K. (2004). Migrant Agricultural Workers and Processes of Social Inclusion in Rural Canada: Encuentros and Desencuentros. Can. J. Latin Am. Caribbean Stud. Spec. Issue. Int. Migration Americas 29 (57-58), 203-239. doi:10.1080/08263663.2004.10816857

Preibisch, K. (2012). Migrant Workers and Changing Work-Place Regimes in Contemporary Agricultural Production in Canada. Int. J. Sociol. Agric. Food 19 (1), 62-82.

Preibisch, K. (2010). Pick-your-own Labor: Migrant Workers and Flexibility in Canadian Agriculture. Int. Migration Rev. 44 (2), 404-441. doi:10.1111/j.17477379.2010.00811.x

Program related costs (2021). Foreign Agricultural Resource Management Service. Available at: https://farmsontario.ca/things-to-know/program-related-costs/

Rapid Response Service (2013). Migrant Farm Workers and Sexual Health. Ontario HIV Treatment Network. Available at: https://www.ohtn.on.ca/rapid-response70-migrant-farm-workers-and-sexual-health/

Robinson, D. (20162014). Fairclough, NormanLanguage and Power. J. Lang. Polit. 15 (1), 116-119. doi:10.1075/jlp.15.1.06rob

Rosiek, L. R., Snyder, J., and Pratt, S. L. (2019). The New Materialisms and Indigenous Theories of Non-human agency: Making the Case for Respectful Anti-colonial Engagement. Qual. Inq., 1-6. doi:10.1177/1077800419830135

Satzewich, V. (2007). Business or Bureaucratic Dominance in Immigration Policymaking in Canada: Why Was Mexico Included in the Caribbean Seasonal Agricultural Workers Program in 1974. J. Int. Migration Integration 8, 255-275. doi:10.1007/s12134-007-0026-8

Saylors, K. (2019). Labour Advocate Decries Death in Norwich Crash. Woodstock Sentinel-Review, July 16. Available at: https://www.woodstocksentinelreview. $\mathrm{com} /$ news/localnews/labour-advocate-decries-death-in-norwich-crash

U.S. Department of Health and Human Services (2001). "Simple Solutions: Ergonomics for Farm Workers," in U.S. Department of Health and Human Services. Editors S. Baron, C. F. Estill, A. Steege, and N. Lalich. February. Retrieved from http://www.migrantworkerhealth.ca/Resources.html.

Sheldahl-Thomason, S. (2018). Discourse, Documents, and Counter-discipline: Michel Foucault's Ethics and the Practice of Writing. West Lafayette, IN: Purdue UniversityProQuest Dissertations, 10791913. [Doctoral dissertation.

Sheldahl-Thomason, S. (2019). Foucault and the Use of Exposure: Discipline, Ethics, and Self-Writing. Rev. Commun. 19 (3), 225-240. doi:10.1080/ 15358593.2019.1635710

Shin, J., and Ging, L. (2019). "Producing Human Capital": A Critical Discourse Analysis of Title II of the Workforce Innovation and Opportunity Act (WIOA). Adult Edu. Q. 69 (3), 163-183. doi:10.1177/0741713619834663
Silverman, S. J., and Hari, A. (2016). Troubling the fields: Choice, Consent, and Coercion of Canada's Seasonal Agricultural Workers. Int. Migration 54 (5), 91-104. doi:10.1111/imig.12266

Simon, P. (2016). Cycling Accident Claims Life of Migrant Near Hamilton. Vice and Hunter, September 5. Available at: https://www.viceandhunter.ca/blog/ 2016/09/cycling-accident-claims-life-ofmigrant-worker-near-hamilton.shtml

Statistics Canada. (2020). COVID-19 Disruptions and Agriculture: Temporary Foreign Workers. Statistics Canada, April 17. Available at: https://www150. statcan.gc.ca/n1/pub/45-28-0001/2020001/article/00002-eng.htm

Strauss, K., and McGrath, S. (2017). Temporary Migration, Precarious Employment and Unfree Labour Relations: Exploring the "Continuum of Exploitation" in Canada's Temporary Foreign Worker Program. Geoforum 78, 199-208. doi:10.1016/j.geoforum.2016.01.008

Thomas, M., Choudry, A., and Smith, A. (2016). "Producing and Contesting "Unfree Labour" through the Seasonal Agricultural Worker Program," in Unfree Labour? Struggles of Migrant and Immigrant Workers in Canada. Editors A. Choudry and A. Smith (Michigan, USA: PM Press), 21-36.

United Food and Commercial Workers Canada and Agricultural Worker Alliance. (2020). The Status of Migrant Workers in Canada, 2020 Special Report: Marking Three Decades of Advocacy on Behalf of Canada's Most Exploited Workforce. United Food and Commercial Workers Canada and Agricultural Worker Alliance. Available at: http://www.ufcw.ca/templates/ufcwcanada/ images/awa/publications/UFCW-Canada-Status-of-Migrant-Workers-Report2020.pdf

Vickers, T., and Rutter, A. (2018). Disposable Labour, Passive Victim, Active Threat: Migrant/non-Migrant Othering in Three British Television Documentaries. Eur. J. Cult. Stud. 21 (4), 486-501. doi:10.1177/1367549416682968

Vosko, L. F. (2013). National Sovereignty and Transnational Labour: The Case of Mexican Seasonal Agricultural Workers in British Columbia, Canada. Ind. Relations J. 44 (5-6), 514-532. doi:10.1111/irj.12033

Vosko, L. (2018). Legal but Deportable: Institutionalized Deportability and the Limits of Collective Bargaining Among Participants in Canada's Seasonal Agricultural Workers Program. ILR Rev. 71 (4), 882-907. doi:10.1177/0019793918756055

Weiler, A. M., and McLaughlin, J. (2019). Listening to Migrant Workers: Should Canada's Seasonal Agricultural Worker Program Be Abolished. Dialect Anthropol. 43, 381-388. doi:10.1007/s10624-019-09563-4

Wilhelm, T. (2013). Alleged Drunk Driver Arrested after Hitting Cyclist, Fleeing Scene (With Video Windsor Star, May 6. Available at: https://windsorstar.com/ news/local-news/alleged-drunkdriver-arrested-after-hitting-cyclist-andfleeing-the-scene

Wolkowitz, C. (2006). Bodies at Work. London, UK: SAGE.

Conflict of Interest: The author declares that the research was conducted in the absence of any commercial or financial relationships that could be construed as a potential conflict of interest.

Publisher's Note: All claims expressed in this article are solely those of the authors and do not necessarily represent those of their affiliated organizations, or those of the publisher, the editors and the reviewers. Any product that may be evaluated in this article, or claim that may be made by its manufacturer, is not guaranteed or endorsed by the publisher.

Copyright $\odot 2021$ Clause. This is an open-access article distributed under the terms of the Creative Commons Attribution License (CC BY). The use, distribution or reproduction in other forums is permitted, provided the original author(s) and the copyright owner(s) are credited and that the original publication in this journal is cited, in accordance with accepted academic practice. No use, distribution or reproduction is permitted which does not comply with these terms. 